\title{
Academically At-Risk Students' Initial Motivations and Pre-Graduation Reasons for Attending University
}

Boenell Kline, Mary Katherine Duncan

The purpose of this study was to explore academically at-risk students' initial motivations for enrolling in university, pre-graduation reasons for attending university, and perceptions of the mission of higher education. We defined academically at-risk students as those with a higher than average likelihood of not completing the baccalaureate degree. Participants included 64 undergraduate students (72\% women, 40\% first-generation, $52 \%$ Caucasian, $M_{\text {age }}=22.48$ years). Responses to an online survey indicated that career/materialism (59\%), personal growth (48\%), opportunities/experiences (43\%), and academic-intellectual growth (40\%) were the most frequently reported enrollment motivations. Personal growth (67\%) and career-materialism (45\%) were the most commonly reported pre-graduation reasons for attending university. Additionally, the majority of participants perceived students' personal growth (55\%) to be the mission of higher education. Data may inform academic and non-academic programming aimed at maximizing academically at-risk students' likelihood of success in higher education.

Keywords: at-risk students, enrollment motivations, reasons for attending university, mission of higher education

\section{Introduction}

Research has documented wide-ranging benefits associated with earning a bachelor's degree. For example, Ma, Pender, and Welch (2016) found that individuals with at least a bachelor's degree earn more money and are less likely to be unemployed than individuals without a bachelor's degree. These economic benefits seem to extend beyond the traditional college graduate. For example, Salazar (2013) noted that individuals who aged out of foster care and earned at least a bachelor's degree found jobs at nearly the same rate and same pay as

Boenell Kline, Bloomsburg University of Pennsylvania

Dr. Mary Katherine Duncan, Bloomsburg University of Pennsylvania

\section{Authors' Note}

This research was funded by Bloomsburg University's Office of the Provost and the Joan and Fred Miller Distinguished Professor of Good Work Fellowship. It was also made possible by support from Bloomsburg University's Office of Planning and Assessment, including the assistance of Dr. Jerrold Harris. 
graduates who were never enrolled in the foster care system. Similarly, Cataldi, Bennett, and Chen (2018) found that first-generation college graduates were employed at nearly the same rate with similar yearly incomes as individuals who were not first-generation students. In addition, individuals with at least a bachelor's degree are more likely to lead healthier lifestyles (e.g., more likely to exercise, less likely to smoke), to be covered by employer-provided health insurance, and to enjoy good health (Ma, et al., 2016; Zajacova, Hummer, \& Rogers, 2012). They also appear to be more likely than individuals who have not earned a bachelor's degree to demonstrate civic engagement such as volunteerism and voting ( $\mathrm{Ma}$, et al., 2016).

Given these findings, it is not surprising that the number and diversity of people pursuing a degree in higher education has grown. The National Center for Education Statistics estimated that student enrollment increased from 17.3 million to 20.2 million between 2004 and 2014 (Snyder, de Brey, \& Dillow, 2016). In addition, Snyder, et al. (2016) found increases in the enrollment of Hispanic, African American, and Asian/Pacific Islander students. In 2015, more than onethird (36\%) of the U. S. adult population between the ages of 25 and 34 had earned at least a bachelor's degree (Ma, et al., 2016).

America's system of higher education has seen changes in not only its enrollment profile but also its mission. Ford (2017) summarized changes from higher education's early 17 th century beginnings as a means to perpetuate Christian civilization, to its mid-19th century land grant colleges that focused on the pursuit of practical knowledge and skills in service of the nation. Ford also described the development of research universities that prioritized knowledge in pursuit of truth rather than applied knowledge in pursuit of practical solutions. With the development of for-profit universities, Ford asserted that the American system of higher education has increasingly shifted its focus from one of public good to that of private gain where students seek to acquire marketable skills to bolster their prospects of obtaining a good job and building personal wealth.

As undergraduate students' demographics have broadened and the purpose of higher education has expanded, it is reasonable to expect that motivations for pursuing a bachelor's degree may reflect these changes. In fact, research on generational differences in students' motivations to attend college support Ford's (2017) overview of the shifting functions of higher education. Using a nationally representative sample of 8 million students who enrolled in college between 1971 and 2014, Twenge and Donnelly (2016) found that Generation X students (1980s-1990s) and Millennials (2000s-2010s) reported more extrinsic reasons for attending college (i.e., to make more money) compared to Baby Boomers (1960s and 1970s). In addition, Twenge and Donnelly (2016) found that the internal reasons for attending college (i.e., self-acceptance) were less common among Generation X students and Millennials compared to Baby Boomers. Kennett, Reed, and Lam's (2011) study of 132 undergraduate students ( $M_{\text {age }}=20.86$ years, 87\% female, 52\% first-year) noted similar findings. Specifically, Kennett et al. (2011) found the extrinsic motivator of career/money was the most common central reason for attending college ( $62 \%$ first-year and $60 \%$ upper-year students) and 
intrinsic motivators such as goal achievement (29\% first-year and 24\% upper-year students) and self-improvement (20\% first-year and 37\% upper-year students) were less common central reasons for pursuing a degree in higher education.

Understanding why students enroll in university is important insofar as research has linked motivations for attending college to student outcomes. In a study of 276 Canadian undergraduates, Côté and Levine (1997) identified five major motivations for attending college: careerist-materialist, personal-intellectual development, humanitarian, expectation-driven, and default. The authors found that career-materialist and personal-intellectual development motivations predicted better self-management and self-motivation skills. In a survey of 2,520 college students ( $68 \%$ female; $22 \%$ students of color; $62 \%$ community college and $38 \%$ 4 -year liberal arts college), Guiffrida, Lynch, Wall, and Abel (2013) noted that intrinsic motivations (i.e., autonomy and competence) were positively related to academic achievement and persistence. Similarly, in a study of 481 undergraduates ( $80 \%$ female, $M_{a g e}=20.54$ years, $66 \%$ in first year of study, $73 \%$ Canadian citizens), Kennett, Reed, and Stuart (2013) found that intrinsic motivations (e.g., like learning, for the challenge, to study more critically a broad range of subjects) corresponded to better adjustment, higher grades, and higher levels of academic self-efficacy and resourcefulness.

Given the apparent link between students' motivation for attending college and academic success, it may be especially important to understand the enrollment motivations of students who may be at-risk of not completing their degree program. In a study of 276 nontraditional-aged college students ( 25 years old and older; $57 \%$ community college and $43 \%$ four-year institution), Broekemier (2002) found top motivators included extrinsic reasons (i.e., 58\% "to get a better job with another employer" and 32\% "job advancement with current employer") and intrinsic reasons (i.e., 49\% "gain general knowledge" and 41\% "enhancement of self-esteem"). In addition, Phinney, Dennis, and Osorio's (2006) study of 713 ethnically diverse freshmen $\left(M_{\text {age }}=18.1\right.$ years; $68 \%$ were female; $24 \%$ were firstgeneration; 65\% Latino, 23\% Asian American, 8\% African American, 4\% European American) noted that career/materialism motives and personal-intellectual motives (a single scale in this study) were commonly endorsed across all ethnic groups. Consistent with Côté and Levine (1997), these career/personal motives were associated with successful college adjustment (i.e., self-efficacy, self-confidence, and commitment to college).

Studies of academically at-risk students' enrollment motivations also have identified additional motivation themes. For example, in a study of 207 students, Bui (2002) found that first-generation college students $(n=64)$ were more likely than continuing-generation students to report motives such as gaining respect/ status, bringing honor to their family, and helping their families financially. Similarly, Phinney et al. (2006) identified enrollment motivations such as helping family, encouragement, and proving oneself. Because academically at-risk students may bring with them additional reasons for attending college, it is important to gain a richer understanding of these reasons in order to facilitate their interactions with, integration into, and persistence in the college environment. Accordingly, 
the purpose of this study was to explore academically at-risk students' reasons for attending college as well as to study their perceptions of the purpose of higher education. Based on the available literature, we expected to find both internal and external reasons for academically at-risk students to pursue a degree in higher education. We also wondered if academically at-risk students would report similar patterns of reasons for attending university as they approached graduation. In addition, we expected to find support for motivations (e.g., make family proud and help family financially) identified by Bui's (2002) and Phinney et al's (2006) studies of at-risk students. Finally, we were interested to see whether academically at-risk students' enrollment motivations and pre-graduation reasons for attending university aligned with their perceived mission of higher education.

\section{Method}

This study was part of a more extensive research project on academically atrisk students' pursuit of purpose in higher education. The larger study included two parts. Part 1 included an online survey. Part 2 included a follow-up interview. This manuscript focuses on the methodology, measures, and findings pertaining to select items from Part 1. Specifically, self-report data regarding students' initial motivations for enrolling in university, their pre-graduation thoughts about why individuals should attend university, and their views on the university's mission are summarized below.

\section{Participants}

We conducted this study at a public university in northeastern Pennsylvania that serves approximately 9000 undergraduates and 600 graduate students $(57.7 \%$ female; $79.1 \%$ White). We were interested in learning about undergraduates' motivations for pursuing a college degree and exploring how well these motivations align with their perception of the mission of the university. We were especially interested in learning more about the perspectives of students who, upon entering the university, may have been considered academically at-risk for not graduating but who, at the time of this study, were on track to earn a baccalaureate degree. Specifically, all participants had earned a minimum 2.5 GPA and completed a minimum of 90 credits of coursework (i.e., senior status). In addition, all participants met at least one of two additional criteria. The first of these additional criteria was enrollment in a developmental education course upon entering the University. At our University, incoming students are scheduled into developmental courses when their academic history (e.g., prior coursework, grades, standardized test scores) indicates that they might be underprepared for college-level work. The second of these additional criteria was self-identification as a member of a racial or ethnic minority group at our predominantly white institution. A report by the National Student Clearinghouse Research Center (Shapiro, Dundar, Huie, et al., 2017) noted that, among students who started in four-year public institutions, 
six-year completion rates of black and Hispanic students (45.9\% and 55.0\%, respectively) were lower than white students (67.2\%). The report also noted that, among students who started in any type of college or university in Fall 2010, six-year completion rates of black and Hispanic students $(45.8 \%$ and $38.0 \%$, respectively) fell below the national average (54.8\%) and below the completion rates of white students $(62.0 \%)$.

Of the 519 eligible undergraduates, 73 students began the survey. Nine failed to complete the survey, resulting in a $13 \%$ response rate. In the end, participants included $N=64$ undergraduate students ( $72 \%$ women; $M_{\text {age }}=22.48$, age range 20 - 40 years old). Of these participants, $40.6 \%$ were first-generation students. Most participants $(78.1 \%)$ indicated graduation dates during the current academic year. Participants identified as Caucasian 52\%, Black or African American 22\%; Hispanic or Latino 13\%; Asian or Pacific Islander 3\%; and "Other" 11\%.

\section{Materials}

An online Qualtrics ${ }^{\circledR}$ survey was designed for the purpose of this study. After reading and endorsing the study's Letter of Informed Consent, participants completed several demographic items (e.g., age, biological sex, graduation date, ethnicity, and first-generation status). Next, participants responded to the following question: "Think back to when you first arrived here. Why did you come to college?" Participants could choose up to three responses from a randomized list of 17 options (including a write-in option) to indicate the most important initial reasons for enrolling in college. Then, participants answered an open-ended question that asked, "Now that you are preparing to graduate, how would you answer someone who asks, "Why should I go to college?" Participants responded to a second open-ended item which read, "In your opinion and based on your experiences, what is the University's mission?" The online survey included other items that are not relevant to this report. The median time to complete the entire survey was $M d n=26.19$ minutes.

\section{Procedure}

After receiving approval from our university's Institutional Review Board, the investigators sent prospective participants a recruitment email that included a link to the online Qualtrics survey. Upon indicating their fully informed consent, participants independently completed the survey. After 5 weeks, prospective participants received a reminder of the invitation to volunteer their participation in the study through a follow-up email. Upon completion of both parts of the study (i.e., online survey and follow-up interview), participants received a \$50 Amazon gift card. 
With respect to the question about their initial motivations for enrolling in college, data were removed for six participants $(N=58)$ who did not follow the directions (i.e., they selected more than three responses). Most participants (78\%) named three reasons for attending college; however, several selected only one reason (14\%) and a few identified two reasons (9\%). Response options were collapsed into six categories (See Table 1).

Next, the two authors independently read participants' responses to each of the open-ended questions. For each question, the authors independently made lists of themes in participants' responses. Then, the authors compared themes and mutually agreed on using the same six coding categories as above. Examples of participants' written responses for each category are presented in Table 1. Constructing a coding rubric from these categories, the authors independently coded participants' responses. If a participant gave more than one reason, the response was coded into as many categories as applied; however, a specific category was only counted once in a participant's response. Cohen's Kappa analyses indicated very good interrater reliability across the categories for each open-ended question ( $\kappa=91.6$ and $\kappa=86.1$, respectively).

TABLE 1

\section{Categories and examples of participants' enrollment motives, pre-graduation reasons for attending university, and perceived missions of higher education}

\begin{tabular}{|c|c|c|c|}
\hline Category & Enrollment Motives & Pre-graduation Reasons & Perceived Missions \\
\hline Opportunities/ & Fresh start & "...to experience & "To explore new \\
\hline Experiences & $\begin{array}{l}\text { Change of scenery } \\
\text { Extracurriculars }\end{array}$ & new things." & experiences." \\
\hline Personal Growth & $\begin{array}{l}\text { Figure out who I am } \\
\text { Achieve independence } \\
\text { Financial responsibility }\end{array}$ & $\begin{array}{l}\text { "You will learn more } \\
\text { about you." }\end{array}$ & $\begin{array}{l}\text { "To allow you to be } \\
\text { yourself." }\end{array}$ \\
\hline Career-Materialism & $\begin{array}{l}\text { Graduate school } \\
\text { Good job } \\
\text { Money }\end{array}$ & $\begin{array}{l}\text { "...it helps you further } \\
\text { your career." }\end{array}$ & $\begin{array}{l}\text { "To get students } \\
\text { ready for the } \\
\text { professional world." }\end{array}$ \\
\hline Academic-Intellectual & 1 Learn new things ". & ...the best way to gain & "To advance the \\
\hline & $\begin{aligned} & \text { Learn about interests } \mathrm{k} \\
& \mathrm{y}\end{aligned}$ & $\begin{array}{l}\text { knowledge about something } \\
\text { you're interested in" }\end{array}$ & learning of students" \\
\hline Social & $\begin{array}{l}\text { Have fun } \\
\text { Make friends }\end{array}$ & $\begin{array}{l}\text { "College gives you the } \\
\text { change to meet new people." }\end{array}$ & $\begin{array}{l}\text { "Giving them the } \\
\text { connection to make } \\
\text { friends" }\end{array}$ \\
\hline Other & $\begin{array}{l}\text { Others expected it } \\
\text { Make family proud }\end{array}$ & "Why not give it a try?" & "Don’t know" \\
\hline
\end{tabular}




\section{Results and Discussion}

With respect to enrollment motivators, Table 2 shows the most common enrollment motivation was career-materialism (59\%). With respect to careermaterialism, 59\% mentioned the goal of securing a good job, 29\% cited the objective of gaining admission to graduate school, and 26\% reported the desire to earn more money. These data are consistent with Ford's (2017) overview of the changing focus of higher education as well as studies by Kennett et al. (2011), Phinney et al. (2006), and Twenge and Donnelly (2016) showing that enrollment motivators tend to be external and related to social mobility or personal gain. In addition to reflecting current trends, these findings suggest our academically at-risk participants entered the university with aspirations to achieve a decent quality of life through gainful employment. These findings are also encouraging because the external motive of career-materialism has been linked to self-management and self-motivation (Côté \& Levine, 1997) as well as self-efficacy, self-confidence, and commitment to college (Phinney et al., 2006).

A substantial minority of participants (43\%) also reported that the external motivator of opportunities/experiences influenced their enrollment in higher education. Of these participants, the most common reason was seeking a fresh start (48\%) followed by wanting a change of scenery (36\%) and pursuing extracurricular activities (28\%). In addition, almost half of participants (48\%) reported that the internal motivator of personal growth influenced their decision to enroll in college. Of these participants, the most common reason was 'figure out who I am' (61\%) followed by 'achieve independence' (39\%). Collectively, these data suggest that a notable proportion of our participants approached college with the expectation that it would afford them an opportunity to explore their interests,

TABLE 2

\section{Percentages of participants' enrollment motives, pre-graduation reasons for attending university, and perceived missions of higher education}

\begin{tabular}{lccc} 
Category & $\begin{array}{c}\text { Enrollment } \\
\text { Motives }\end{array}$ & $\begin{array}{c}\text { Pre-graduation } \\
\text { Reasons }\end{array}$ & $\begin{array}{c}\text { Perceived } \\
\text { Missions }\end{array}$ \\
\hline Opportunities/Experiences & 43 & 25 & 8 \\
Personal Growth & 48 & 67 & 55 \\
Career-Materialism & 59 & 45 & 31 \\
Academic-Intellectual & 40 & 36 & 35 \\
Social & 33 & 20 & 2 \\
Other & 14 & 8 & 5
\end{tabular}


discover their abilities, and decide for themselves how to use these positive traits as they transition into adult roles and assume adult responsibilities. We believe that these findings add to the available literature insofar as measures commonly used to assess young people's motivations for attending university do not include reasons related to self-exploration or self-discovery (Broekemier, 2002; Bui, 2002; Côté \& Levine, 1997). We are also encouraged by these findings because they suggest academically at-risk students may enroll in university actively seeking meaningful aspirations and activities in pursuit of identity formation and a life of purpose. Future research might focus on these relatively unexplored motives to examine their potential influence on academically at-risk students' outcomes. In addition, future research might explore what high-impact academic practices or extracurricular programming support these motivations.

We also noted that $40 \%$ of participants identified the internal motivation of academic-intellectual growth. Of these participants, 39\% reported enrolling in university to learn something new, and $61 \%$ reported enrolling in university to learn more about something that interested them. Our academic-intellectual growth category resembled Guiffrida et al.'s (2013) Autonomous Motivation Scale (i.e., 'because I enjoy learning new things' and 'because my studies allow me to continue to learn about many new things that interest me') and Bartram's (2016) Personal Development factor (i.e., 'I want to explore new ideas' and 'I love learning'). We were encouraged that academic-intellectual growth was identified as a relatively common enrollment motivator because similar internal motivations have been associated with academic achievement and persistence (Guiffrida et al., 2013).

Table 2 also summarizes participants' pre-graduation reasons for attending university. Similar to enrollment motivations, career-materialism (45\%) and personal growth $(67 \%)$ were the most common pre-graduation motives reported by participants. This finding adds to the available literature because, unlike other studies that asked freshmen and higher-year students about their enrollment motivations, we asked higher-year students to imagine they were advising prospective students about the value of higher education after years of collegiate experiences. When comparing participants' initial enrollment motivations and their pre-graduation reasons for attending university, an interesting trend begins to emerge. Specifically, career-materialism motives (e.g., get a good job, make connections, improve quality of life) decreased from $59 \%$ (enrollment) to $45 \%$ (pre-graduation) while personal growth motives (e.g., "College helps young adults become independent and figure out who they are.") increased from $48 \%$ (enrollment) to $67 \%$ (pre-graduation). Future research might examine whether this trend is replicable and statistically significant. If this finding is robust, then future research might also explore when and under what conditions personal growth motives begin to play a relatively more prominent role for undergraduate students.

Finally, Table 2 summarizes participants' perceptions of the mission of higher education. The majority of participants (55\%) reported that personal growth (e.g., figuring out who you are and what you want to do, becoming the best you, 
achieving your own goals, and preparing to enter the world as an independent adult) comprises the university's main objective. This finding may not be too surprising from the vantage point of developmental psychology. Over the last few decades, the discipline of psychology has adopted the concept and term of emerging adulthood to characterize a developmental period that falls between adolescence and adulthood. Data from this study suggest that academically at-risk undergraduate students may perceive higher education as a formative time and venue for addressing the psychosocial developmental task of identity formation. Along these lines, future research might investigate curricular and extracurricular programming that maximizes higher education's role in providing a constructive and productive experience for young people who are on the edge of emerging into adult roles and responsibilities.

Contrary to expectation, we did not find support for motivators identified by Bui's (2002) first-generation freshmen (i.e., gain respect/status, bring honor to family, and help family financially after graduation) or Phinney et al's (2006) focus groups of ethnically diverse freshmen (i.e., help family, encouragement from others, and prove oneself). One explanation may be that we did not include these reasons among the list of 17 motives from which participants could select their top three enrollment motivations. We did, however, offer participants a write-in option. Only eight participants wrote in responses, and none of these responses matched those identified by Bui or Phinney et al. Another reason may be that we did not use follow-up focus groups as did Phinney et al. Such opportunities for conversations with like-minded peers may have permitted additional themes to emerge. We also noted demographic differences that may have affected each study's findings. For example, almost two-thirds of Phinney et al's sample was Latino; whereas, only $13 \%$ of our sample identified as Hispanic/Latino and the majority of our sample identified as Caucasian. Furthermore, Phinney et al. and Bui noted that motives pertaining to helping one's family characterized students from the lowest socioeconomic status backgrounds. We did not collect data about our participants' socioeconomic status. Finally, new categories identified by Bui and Phinney et al. were reported by freshmen. Our sample, in contrast, comprised students who were nearing graduation. It could be that motives related to gaining respect/status, bringing honor to families, helping families out financially, and proving oneself are no longer the most salient goals of pre-graduation students.

Motives related to enrolling in or attending college in order to contribute to something beyond oneself are also absent from our study's findings. The absence of such findings may be a function of not including them as options in our list of 17 motives from which participants were invited to select their top three enrollment motivations. However, participants were given a write-in option. None of the eight write-in responses referred to benefitting others or contributing to the democracy. In their pre-graduation reasons for attending college, only one participant reported they would tell someone who was contemplating pursuing a degree in higher education to do so specifically to serve something beyond themselves and just three respondents indicated that part of the mission of higher education was to cultivate good citizens. Current literature is mixed regarding students' beyond-the- 
self motives. Kennett et al. (2011) found that contributing to society was rarely reported as a central reason for attending college (1.45\% of first year and $6.35 \%$ of upper year students). In contrast, Bartram's (2016) tri-national study showed that altruism was a commonly reported motivation for attending college. It should be noted, however, that Bartram's study excluded economic motivations and targeted education students whose vocation is decidedly one of service to others.

The purpose of this study was to gain a deeper understanding of academically at-risk students' reasons for attending college as well as to study their perspectives on the purpose of higher education. Findings from this study are preliminary. Our relatively homogenous sample (primarily White and female) and low response rate $(13 \%)$ suggest our findings may not be representative of the entire population of interest. Also, given that this study was conducted at a single, public university in northeastern Pennsylvania, our findings have limited generalizability to other types of institutions (e.g., private university and community colleges) in other geographical locations. Despite these limitations, data offered support for the current literature with respect to the prevalence of external motivators for enrolling in higher education. Data also suggested growing consensus regarding intrinsic motivations for attending college over time. Furthermore, we noted relatively unexplored motives for academically at-risk students' enrollment such as opportunities/experiences (i.e., a fresh start and change of scenery) as well as personal growth (i.e., self-exploration and self-discovery). We hope that these findings will contribute to conversations about curricular and extracurricular programming aimed at maximizing academically at-risk students' retention and success in higher education.

\section{References}

Bartram, B. (2016). 'Career and money aside, what's the point of university?' A comparison of students' non-economic entry motives in three European countries. Higher Education Quarterly, 70(3), 281-300.

Broekemier, G. M. (2002). A comparison of two-year and four-year adult students: Motivations to attend college and the importance of choice criteria. Journal of Marketing for Higher Education, 12(1), 31-48.

Bui, K. V. T. (2002). First generation students at a four-year university: Background characteristics, reasons for pursuing higher education, and first-year experiences. College Student Journal, 36(1), 3-11.

Cataldi, E. F., Bennett, C. T., \& Chen, X. (2018). First-Generation Students: College Access, Persistence, and Postbachelor's Outcomes. Stats in Brief (NCES 2018421). U.S. Department of Education. Washington, DC: National Center for Education Statistics. Retrieved from https://nces.ed.gov/pubs2018/2018421.pdf

Côté, J. E., \& Levine, C. (1997). Student motivations, learning environments, and human capital acquisition: Toward an integrated paradigm of student development. Journal of College Student Development, 38(3), 229-242. 
Ford, M. (2017). The functions of higher education. American Journal of Economics and Sociology, 76(3), 559-578.

Guiffrida, D. A., Lynch, M. F., Wall, A. F., \& Abel, D. S. (2013). Do reasons for attending college affect academic outcomes? A test of a motivational model from a self-determination theory perspective. Journal of College Student Development, 54(2), 121-139.

Kennett, D. J., Reed, M. J., \& Lam, D. (2011). The importance of directly asking students their reasons for attending higher education. Issues in Educational Research, 21(1), 65-74.

Kennett, D. J., Reed, M. J., \& Stuart, A. S. (2013). The impact of reasons for attending university on academic resourcefulness and adjustment. Active Learning in Higher Education, 14(2), 123-133.

Ma, J., Pender, M., \& Welch, M. (2016). Education pays 2016: The benefits of higher education for individuals and society. New York: The College Board.

Phinney, J. S., Dennis, J., \& Osorio, S. (2006). Reasons to attend college among ethnically diverse college students. Cultural Diversity and Ethnic Minority Psychology, 12(2), 347-366.

Salazar, A. M. (2013). The value of a college degree for foster care alumni: Comparisons with general population samples. Social Work, 58(2), 139-150.

Shapiro, D., Dundar, A., Huie, F., Wakhungu, P., Yuan, X., Nathan, A. \& Hwang, Y. A. (2017). Completing college: A national view of student attainment rates by race and ethnicity - Fall 2010 cohort (Signature Report No. 12b). Herndon, VA: National Student Clearinghouse Research Center.

Snyder, T. D., de Brey, C., \& Dillow, S.A. (2016). Digest of Education Statistics 2015 (NCES 2016-014). National Center for Education Statistics, Institute of Education Sciences, U.S. Department of Education. Washington, DC.

Twenge, J. M., \& Donnelly, K. (2016). Generational differences in American students' reasons for going to college, 1971-2014: The rise of extrinsic motives. The Journal of Social Psychology, 156(6), 620-629.

Zajacova, A., Hummer, R. A., \& Rogers, R. G. (2012). Education and health among U.S. working-age adults: A detailed portrait across the full educational attainment spectrum. Biodemography and Social Biology, 58, 40-61. 